\title{
Bidirectional Scattering Distribution Function (BSDF): A Systematized Bibliography
}

\section{Clara Asmail}

National Institute of Standards and Technology, Gaithersburg, MD 20899
In conjunction with the development of a bidirectional scattering mctrology pro. ject, a large number of papers pertaining to the theory and measurement of bidirectional scattcring from optical surfaces were collected and categorized. This collection includes papers that dcal with various aspects of the bidirectional scattering distribution function (BSDF), its measurement, interpretation, use, and implications. Each paper is classified in one or more subject categories on the basis of its technical content. The subject categories are included just to serve as a key to the most salient characteristics of each paper cited. Because of the interest in this field, this bibliography is being published as a service to the public.

Key words: bidirectional reflectance distribution function (BRDF); bidirectional scattering distribution function (BSDF); bidirectional transmittance distribution function (BTDF); coherence; -diffuse reflectance; instrument signature; inverse scattering problem; polarization; scattering theory; specular reflectance; stray light; surface finish.

Accepted: December 13, 1990

\section{Introduction}

The bidirectional scattering distribution function (BSDF) radiometrically characterizes the scatter of optical radiation from a surface as a function of the angular positions of the incident and scattered beams. By definition, it is the ratio of the scattered radiance to the incident irradiance: the unit is inverse steradian. The term bidirectional reflectance distribution function (BRDF) is used when specifically referring to reflected scatter. Likewise, bidirectional transmittance distribution function (BTDF) refers to scatter transmitted through a material.

The bidirectional characterization of elastic scatter from surfaces is a property that is required for the evaluation of elements contained within larger systems that need minimal or controlled scattered light. The need for this information is readily seen in applications such as ring laser gyroscopes and telescopes. This type of information is also requisite for characterization of materials intended for use in temperature control where thermal radiation must be modelled or in imaging applications where stray light must be suppressed. It may also be used to assist the acceptance/rejection process in optical manufacturing settings.

The present state of most of the facilities measuring this quantity needs to be upgraded to support new and more stringent requirements as well as recent strides in the production of high-quality optics.

There is a lack of uniformity throughout the community for physical standards which can ascertain the accuracy of BSDF measurements (paper 91). The NIST Bidirectional Scattering Metrology Project is currently developing an instrument which will later serve to develop standard reference materials as well as a standard measurement technique.

In conjunction with the development of this BSDF instrument, a large number of papers pertaining to the theory and measurement of bidirec- 
tional scattering from optical surfaces were collected and categorized. This collection includes papers that deal with various aspects of the BSDF, its measurement, interpretation, use, and implications.

Each paper is classified in one or more subject categories on the basis of its technical content. The subject categories are included just to serve as a key to the most salient characteristics of each paper cited. In the literature, there is a bibliography (paper 117) of papers published prior to 1975 that relate to scattering from surfaces. Building upon that bibliography, this bibliography includes papers related to BSDF published since that time to the present. Neither the category classification list nor the list of papers is complete. There were two selection criteria used to determine whether a paper should be included in this bibliography: the paper was used during certain phases of the NIST project development and/or it was regarded as relevant and important to the field. However, inclusion or omission from the list does not necessarily imply endorsement or reproval, respectively. This systematized bibliography is sufficiently extensive to be of significant help to workers in the field, and particularly to those just beginning to work in it. For further breadth of information, the reader is suggested to review the conference proceedings from the Society of Photo-Optical Instrumentation Engineers (SPIE) that focus on scattering from surfaces: some papers from each of these are cited here.

\section{Categories}

As an aid to identifying papers related to a certain field, each of the papers is listed under each category in which it has been classified. Due to the wide interdisciplinary nature of optical scattering metrology, some topics had to be grouped together so that the list would not become unmanageable. (In many instances, the title of the articles suggest the information covered.) The subject categories are coded and used as follows:

\section{Abs-Aberrations}

The optical design of a system determines the aberrations that will be present-assuming accurate alignment - and their magnitudes. The calculation of these aberrations and their effect on the measurement of BSDF are addressed in the following papers: $3,96,102,159,160$.

\section{Aprt-Apparatus}

Many different instruments are described in the literature. A sampling of these apparatus overviews is contained in the following papers: $4,12,31,41$, $51,52,63,65,66,76,77,79,83,84,87,89,90,93,94,95,103$, $111,112,132,113,118,120,122,128,129,136,137,138$, $140,145,146,151,159,160,161,166,168,169$.

\section{Calb-Calibration}

Techniques for calibration and/or error analysis include reference methods and absolute methods. Specific details concerning calibration and the philosophy of calibration are discussed in these papers: $23,33,34,83,89,108,145,158$.

\section{Coh-Coherence}

The use of laser sources in BSDF instruments is very common. Coherence becomes a critical property of these sources in diffuse BSDF metrology. The following papers address the property as it pertains to radiometry in general and to BSDF metrology in particular: $3,8,37,39,40,49,59,61,63$, $73,80,97,98,101,125,126$.

\section{Desn-Design}

Design criteria and plans or layouts of components or subsystems of BSDF instruments are separated out and described in detail. These subsystems include source, sample manipulation, receiver, attenuation, apertures, etc: $3,10,11,21,22,27,28,29,31$, $35,41,51,52,60,66,68,69,71,76,85,86,87,89,90,93,94$, $95,108,112,132,118,119,124,128,130,136,141,142,156$, $157,159,160,162,163,166,168,170$.

\section{Diff-Diffraction}

Truncation of optical beams by apertures cause diffraction and thereby affect the instrument signature of BSDF instruments. This effect is discussed in the following papers: $3,49,69,70,72,89,96,139$, 159,160 .

\section{Expt - Experimental Data}

These articles include experimental results in the form of tabulated data or graphs from a variety of different types of measurements. Some of these include data from actual BSDF scans on particular material samples while others give interpretive results highlighting instrument capabilities. Still 
other papers give profilometry data that yield topographic information. The particular type of experimental data given within each paper should be obvious from the title of the paper: $4,5,7$, $9,13,15,16,17,18,20,22,24,25,26,28,29,30,32,35,36,38$, $40,41,42,44,46,48,52,53,54,57,59,64,67,73,76,78,79$, $83,88,91,92,94,99,100,101,103,104,109,110,111,132$, $113,114,115,119,120,121,122,123,127,128,129,130$, $131,133,134,135,138,139,140,142,143,145,147,149$, $151,152,154,158,161,165,167,168,169,170$.

\section{Inst-Instrument Signature}

The background measurement of the noise equivalent BSDF, or the instrument signature, limits an instrument to the measurement of samples that have a BSDF larger than the NEBSDF. Specific instrument profiles or signatures are displayed in some of the following papers. The other papers address general concerns in obtaining and improving the signature of an instrument: 4,12 , $36,76,77,85,86,90,120,124,130,136,137,139,141,151$, $159,160,162,164,166,168,171$.

\section{Matl-Materials/Coatings}

Particular optical materials and/or coatings are identified and experimental BSDF data are given for each of these in the following papers: 2,7,9, $13,16,17,22,24,25,28,29,32,35,42,48,52,53,64,67,76$, $78,83,92,94,99,100,104,109,110,113,114,115,121,122$, $123,129,130,131,133,135,138,145,149158,162,165$,

\section{Polarization}

Polarization control, theory, and associated problems are examined: 5,6,23,24,25,59,79,95,144, 147,167 .

\section{Prof-Profile Analysis Techniques}

Various types of mechanical and optical surface profiling techniques are described and/or compared against optical scattering predictions of surface finish (or the inverse: predictions of optical scatter from surface finish): $1,2,17,20,30,39,43,44$, $46,54,56,57,59,65,88,91,100,109,111,134,137,140,150$, 151.

\section{Stnd-Standard Reference Methods}

The following papers describe techniques used for, or problems in, referencing BSDF measure- ments, thereby assigning a level of confidence to the accuracy of the measurement: 33,53,83,91, $92,108,130,145,158,164$.

\section{Stra - Stray Light}

Control, or suppression, of geometrically stray light is examined in this group of papers. Included in these are some papers which evaluate baffling materials with BRDF data: $18,22,27,28,29,42$, $50,58,60,69,71,78,87,90,113,123,146,149,156,157,163$, 170.

\section{Surv-Survey}

Below is a list of papers that are outstanding in their fields and provide comprehensive coverage of a well-defined topic within BSDF metrology: $19,24,45,46,65,74,76,77,81,82,89,91,92,105,106,107$, $108,117,130,140,148,171$.

\section{Thry-Scattering Theory}

Among the theoretical questions explored throughout these papers are: basic definition of BSDF, scattering theory of surfaces, mathematical treatment of surfaces, subsurface contributions to scatter, inverse scattering problem, and scaling of BSDF with respect to angle of incidence and wavelength: $1,3,5,6,7,8,12,14,15,16,17,18,20,23,26,37,38$, $39,40,43,44,45,46,47,49,55,56,57,58,59,61,62,69,70$, $71,72,74,75,77,79,80,81,82,90,94,96,97,98,101,103$, $105,106,107,108,109,110,111,116,120,124,125,126$, $129,131,134,139,144,146,147,148,150,152,153,154$, $155,156,157,161,162,167,170$.

\section{Topo-Topography/Surface Finish}

Surface roughness and sample isotropy, homogeneity, and cleanliness are all topographic contributions to optical scatter. These topics as well as some subsurface contributions are treated in the following papers: $1,2,4,9,14,15,16,17,18,19,20,30$, $38,39,40,43,44,45,46,47,54,55,56,57,62,74,75,88,100$, $109,110,111,116,120,121,125,127,134,135,139,142$, $144,147,150,152,153,154,155,161,162,167,169$.

\section{Tran - Transmitted Scatter}

Issues related to the bidirectional transmittance distribution function, BTDF, are considered in these papers: $52,103,122,126$. 


\section{Bibliography}

The papers are listed below in alphabetical order according to first author and are numbered. The related topic codes are listed alphabetically in the line immediately following the citation.

1. Al-Jumaily, G. A., Wilson, S. R., and McNeil, J. R., Frequency Response Characteristics of an Optical Scatterometer and a Surface Profilometer, SPIE Proceedings, 675 (1986).

Prof Thry Topo

2. Al-Jumaily, G. A., Wilson, S. R., McNally, J. J., McNeil, J. R., Bennett, J., and Hurt, H. H., Influence of Metal Films on the Optical Scatter and Related Micro-Structure of Coated Surfaces, Appl. Opt. 25, 20 (1986) p. 3631. Matl Prof Topo

3. Allred, D. B., and Mills, J. P., Effect of Aberrations and Apodization on the Performance of Coherent Optical Systems 3: The Near Field, Appl. Opt. 28, 4 (1989) p. 673. Abs Coh Desn Diff Thry

4. Amra, C., Grezes-Besset, C., Roche, P., and Pelletier, E., Description of a scattering apparatus: application to the problems of characterization of opaque surfaces, Appl. Opt. 28, 14 (1989) p. 2723.

Aprt Expt Inst Topo

5. Bahar, E., and Fitzwater, M., Like- and Cross-Polarized Scattcring Cross Sections for Random Rough Surfaces: Theory and Experiment, J. Opt. Soc. Am. A., 2, 12 (1985) p. 2295. Expt Pol Thry

6. Bahar, E., and Fitzwater, M., Full-Wave Copolarized Nonspecular Transmission and Reflection Scattering Matrix Elements for Rough Surface, J. Opt. Soc. Am., A., 5, 11 (1988) p. 1873. Pol Thry

7. Baltes, H., and Wolfe, W., K Correlations and Facet Models in Diffuse Scattering: Experimental Evaluation, Opt. Lett., 5, 12 (1980) p. 549. Expt Matl Thry

8. Baltes, H., Steinle, B., Jakeman, E., and Hoenders, B., Diffuse Reflectance and Coherence, Infrared Phys., 19 (1979) p. 461. Coh Thry

9. Barnes, W., Jr, and McDonough, R., Low Scatter Finishing of Aspheric Optics, Opt. Eng., 18, 2 (1979) p. 143. Expt Matl Topo

10. Bartell, F., Infrared Calibration: Very Low Signals May Have Very Large Errors, SPIE Proceedings, 499 (1984) p. 108.

Desn

11. Bartell, F., BRDF Measurement Equipment Intrinsic Design Considerations, SPIE Proceedings, 511 (1984) p. 31. Desn

12. Bartell, F., Dereniak, E., and Wolfe, W., The Theory and Mcasurement of Bidirectional Reflectance Distribution Function (BRDF) and Bidirectional Transmittance Distribution Function (BTDF), SPIE Proceedings, 257 (1980) p. 154. Aprt Inst Thry

13. Bartell, F., Hubbs, J., Nofziger, M., and Wolfe, W., Measurements of Martin Black at $\sim 10 \mu \mathrm{m}$, Appl. Opt., 21, 17 (1982) p. 3178.

Expt Matl
14. Bennett, H., and Ricks, D. W., Effects of Surface and Bulk Defects in Transmitting Materials on Optical Resolution and Scattered Light, SPIE Proceedings, 683 (1986). Thry Topo

15. Bennett, H., and Porteus, J., Relation Between Surface Roughness and Speeular Reflectance at Normal Incidence, J. Opt. Soc. Am., 51, 2 (1961) p. 123. Expt Thry Topo

16. Bennett, H. E., Specular Reflectance of Aluminized Ground Glass and the Height Distribution of Surface Irregularities, J. Opt. Soc. Am., 53, 12 (1963) p. 1389. Expt Matl Thry Topo

17. Bennett, H. E., Scattering Characteristics of Optical Materials, Opt. Eng., 17, 5 (1978) p. 480.

Expt Matl Prof Thry Topo

18. Bennett, H. E., Reduction of Stray Light from Optical Components, SPIE Proceedings, 107 (1977) p. 24. Expt Stra Thry Topo

19. Bennett, J., When is a Surface Clean? Optics and Photonics News (June 1990) p. 29.

Surv Topo

20. Bennett, J., and Dancy, J., Stylus Profiling Instrument for Measuring Statistical Properties of Smooth Optical Surfaces, Appl. Opt. 20, 10 (1981) p. 1785.

Expt Prof Thry Topo

21. Bennett, K., and Byer, R., Computer-Controllable Wedged-Plate Optical Variable Attenuator, Appl. Opt. 19, 14 (1980) p. 2408.

Desn

22. Bergener, D., Pompea, S., Shepard, D., and Breault, R. Stray Light Rejection Performance of SIRTF: A Comparison, SPIE Proceedings, 511 (1984) p. 65. Desn Expt Matl Stra

23. Bickel, W. S., and Bailey, W. M., Stokes Vectors, Mueller Matrices, and Polarized Scattered Light, Am. J. Phys., 53, 5 (May 1985) p. 468.

Calb Pol Thry

24. Biekel, W. S., Zito, R. R., and Iafelice, V., Polarized Light Scattering From Metal Surfaces, J. Appl. Phys., 61, 12 (June 15, 1987) p. 5392. Expt Matl Pol Surv

25. Blau, H. H., Gray, E. L., and Bourioius, G. M. B., Reflection and Polarization Properties of Powder Materials, Appl. Opt., 6, 11 (Nov. 1967) p. 1899.

Expt Matl Pol

26. Blazey, R., Light Scattering by Laser Mirrors, Appl. Opt. 6, 5 (May 1967) p. 831. Expt Thry

27. Breault, R. P., Current Technology of Stray Light, SPIE Proceedings, 675 (1986).

Desn Stra

28. Breault, R. P., Specular Black Vane Cavities, SPIE Proceedings, 384 (1983) p. 90.

Desn Expt Matl Stra

29. Breault, R. P., Problems and Techniques in Stray Radiation Supression, SPIE Proceedings, 107 (1977) p. 2. Desn Expt Matl Stra

30. Bristow, T., and Lindquist, D., Surface Measurements with a Non-Contact Nomarski-Profiling Instrument, SPIE Proceedings, 816 (1987).

Expt Prof Topo

31. Brooks, L., and Wolfe, W., Microprocessor-Based Instrumentation for Bidirectional Reflectance Distribution Function (BRDF) Measurements, SPIE Proceedings, 257 (1980) p. 182. Aprt Desn 
32. Brooks, L., Hubbs, J., Bartell, F., and Wolfe, W., Scattering Characteristics of Martin Black at $118 \mu \mathrm{m}$, Appl. Opt., 21, 14 (1982) p. 2465.

Expt Mat

33. Cady, F. M., Bjork, D. R., Rifkin, J., and Stover, J. C., Linearity in BSDF Measurements, SPIE Proceedings, 1165 (1989) .

Calb Stnd

34. Cady, F. M., Bjork, D. R., Rifkin, J., and Stover, J. C., BRDF Error Analysis, SPIE Proceedings, 1165 (1989) . Calb

35. Cady, F. M., Cheever, D. R., Klicker, K. A., and Stover, J. C., Comparison of Scatter Data from Various Bcam Dumps, SPIE Proceedings, 818 (1987).

Desn Expt Matl

36. Cady, F. M., Stover, J. C., Schiff, T. F., Klicker, K. A., and Bjork, D. R., Measurement of Very Near Specular Scatter, SPIE Proceedings, 967 (1988)

Expt Inst

37. Carter, W., and Wolf, E., Coherence Properties of Lambertian and Non-Lambertian Sources, J. Opt. Soc. Am., 65, 9 (1975) p. 1067.

Coh Thry

38. Celli, V., Maradudin, A., Marvin A., and McGurn, A., Some Aspects of Light Scattering from a Randomly Rough Metal Surface, J. Opt. Soc. Am., A., 2, 12 (1985) p. 2225. Expt Thry Topo

39. Chandley, P. J., Surface Roughness Measurements from Coherent Light Scattering, Opt. Quantum Electron., 8 (1976) p. 323.

Coh Prof Thry Topo

40. Chandley, P. J., Determination of the Autocorrelation Function of Height on a Rough Surface from Coherent Light Scattering, Opt. Quantum Electron., 8 (1976) p. 329. Coh Expt Thry Topo

41. Cheever, D. R., Cady, F. M., Klicker, K. A., and Stover, J. C., Design Review of a Unique Complete Angle Scatter Instrument (CASI), SPIE Proce edings, 818 (1987) . Aprt Desn Expt

42. Chocol, C., and Wade, J., Reducing Optical Noise, SPIE Proceedings, 107 (1977) p. 130.

Expt Matl Stra

43. Church, E., and Zavada, J., Residual Surface Roughness of Diamond-Turned Optics, Appl. Opt., 14, 8 (1975) p. 1788.

Prof Thry Topo

44. Church, E., Jenkinson, H., and Zavada, J., Measurement of the Finish of Diamond-Turned Metal Surfaces by Differential Light Scattering, Opt. Eng., 16, 4 (1977) p. 360. Expt Prof Thry Topo

45. Church, E., Jenkinson, H., and Zavada, J., Relationship Between Surface Scattering and Microtopographic Features, Opt. Eng., 18, 2 (1979) p. 125. Surv Thry Topo

46. Church, E., Sanger, G., and Takacs, P., Comparison of Wyko and TIS Measurements of Surface Finish, SPIE Proceedings, 749 (1987) p. 65 .

Expt Prof Surv Thry Topo

47. Church, E. L., Statistical Effects in the Measurement and Characterization of Smooth Surfaces, SPIE Proceedings, 511 (1984) .

Thry Topo

48. Compton, J., Martin, J., and Quinn, T., Some Measurements of Outgassing Properties and Far-Infrared Reflectivities of Two Optical Blacks, J. Phys., 7 (1974) p. 2501. Expt Matl
49. Considine, P. S., Effects of Coherence on Imaging Systems, J. Opt. Soc. Am., 56, 8 (1966) p. 1001.

Coh Diff Thry

50. Crandell, F. F., General Concepts and Approach on Making Stray Light Calculations Without the Use of Large Computers, SPIE Proceedings, 257 (1980) . Stra

51. Davis, L., and Kepros, J., Improved Facility for BRDF/ BTDF Optical Scatter Measurements, SPIE Proceedings, 675, 1 (1986) p. 24. Aprt Desn

52. Dereniak, E., Brod, L., and Hubbs, J., Bidirectional Transmittance Distribution Function Measurements on $\mathrm{ZnSe}$, Appl. Opt., 21, 24 (1982) p. 4421.

Aprt Desn Expt Matl Tran

53. Dereniak, E., Stuhlinger, T., and Bartell, F., Bidirectional Reflectance Distribution Function of Gold-Plated Sandpaper, SPIE Proceedings, 257 (1980) p. 184.

Expt Matl Stnd

54. Detrio, J., and Miner, S., Standardized Total Integrated Scatter Measurements of Optical Surfaces, Opt. Eng., 24, 3 (1985) p. 419.

Expt Prof Topo

55. Eastman, J., and Baumeister, P., The Microstructure of Polished Optical Surfaces, Opt. Commun., 12, 4 (1974) p. 418. Thry Topo

56. Elson, J., and Bennett, J., Vector Scattering Theory, Opt. Eng., 18, 2 (1979) Prof Thry Topo

57. Elson, J., and Bennett, J., Relation Between the Angular Dependence of Scattering and the Statistical Properties of Optical Sufaces, J. Opt. Soc. Am., 69, 1 (1979) p. 31.

Expt Prof Thry Topo

58. Elson, J. M., and Bennett, H. E., Image Degradation Caused by Direct Scatter from Optical Components into the Image Plane, SPIE Proceedings, 511 (1984). Thry Stra

59. Elson, J. M., Rahn, J. P., and Bennett, J. M., Relationship of the TIS from Multilayer-Coated Optics to Angle of Incidence, Polished Correlation Length and Roughness, Appl. Opt., 22, 20 (1983) p. 3207.

Coh Expt Pol Prof Thry

60. Freniere, E. R., First-Order Design of Optical Baffles, SPIE Proceedings, 257 (1980)

Desn Stra

61. Fribert, A. T., Effects of Coherence in Radiometry, SPIE Proceedings, 194 (1979) p. 55.

Coh Thry

62. Fung, A. K., and Chen, M. F., Numerical Simulation of Scattering from Simple and Composite Random Surfaces, J. Opt. Soc. Am., A., 2, 12 (1985) p. 2274.

Thry Topo

63. Gacusan, L., Kwiatkowski, S., Sullivan, B., and Snyder, J., Coherent Heterodyne Scatterometer, SPIE Proceedings, 967 (1988). Aprt Coh

64. Geikas, G. I., Scattering Characteristics of Etched Electroless Nickel, SPIE Proceedings, 257 (1980).

Expt Matl

65. Gillespie, C. H., Edwards, D. F., and Stover, J. C., The Application of Angular Resolved Scatter to the Documentation of Damage to Smooth Mirrors, SPIE Proceedings, 675 (1986).

Aprt Prof Surv 
66. Gilliam, L. E., and Osiecki, R. A., An In-Vacuum BR/TDF Measurement Apparatus, SPIE Proceedings, 675 (1986) . Aprt Desn

67. Grammer, J. R., Bailin, L. J., Blue, M. D., and Perkowitz, S., Absorbing Coatings for the Far-Infrared, SPIE Proceedings, 257 (1980) . Expt Matl

68. Greninger, C. E., Reflective Device for Polarization Rotation, Appl. Opt., 27, 4 (1988) p. 774.

Desn

69. Greynolds, A. W., Simple Formulas for Calculating NearField Diffraction Profiles, SPIE Procecdings, 818 (1987). Desn Diff Stra Thry

70. Greynolds, A. W., Method for Calculating Diffraction Effects in Opto-Mechanical Systems of Arbitrary Geometry, SPIE Proceedings, 257 (1980). Diff Thry

71. Greynolds, A. W., Formulas for Estimating Stray-Radiation Levels in Well-Baffled Optical Systcms, SPIE Proceedings, 257 (1980).

Desn Stra Thry

72. Haas, R. A., Theory of Laser Beam Apodization with a Graded Random Phase Window, Appl. Opt., 27, 13 (1988) p. 2708. Diff Thry

73. Harris, F. S., Jr., Sherman, G. C., and Morse, F. L., Experimental Comparison of Scattering of Coherent and Incoherent Light, IEEE Trans. Antennas and Propag., AP-15, 1 (1967) p. 141. Coh Expt

74. Harvey, J. E., Light-Scattering Characteristics of Optical Surfaces, SPIE Proceedings, 107 (1977) p. 41. Surv Thry Topo

75. Hoenders, B., Jakeman, E., Baltes, H., and Steinle, B., K Correlations and Facet Models in Diffuse Scattering, Opt. Acta, 26, 10 (1979) p. 1307. Thry Topo

76. Hsia, J., and Richmond, J., A High Resolution Laser Bidirectional Reflectometer with Results on Several Optical Coatings, J. Res. Natl. Bur. Stand. (U.S.), 80A, 2 (1976) p. 189.

Aprt Desn Expt Inst Matl Surv

77. Hsia, J. J., and Weidner, V. R., NBS $45^{\circ} /$ Normal Reflectometer for Absolute Reflectance Factors, Metrologia, 17 (1982) p. 92. Aprt Inst Surv Thry

78. Hubbs, J. E., Brooks, L. D., Nofziger, M. J., Bartell, F. O., and Wolfe, W. L., Bidirectional Reflectance Distribution Function of the Infrared Astronomical Satellite SolarShield Material, Appl. Opt., 21, 18 (1982) p. 3323. Expt Matl Stra

79. Iafelice, V. J., and Bickel, W. S., Polarized Light-Scattering Matrix Elements for Select Perfect and Perturbed Optical Surfaces, Appl. Opt., 26, 12 (June 15, 1987) p. 2410. Aprt Expt Pol Thry

80. Jannson, J., Jannson, T., and Wolf, E., Spatial Coherence Discrimination in Scattering, Opt. Lett., 13, 12 (1988) p. 1060. Coh Thry

81. Janeczko, D. J., Power Spectrum Standard for Surface Roughness: Part 1, SPIE Proceedings, 1165 (1989) . Surv Thry

82. Judd, Deane, Terms, Definitions, and Symbols in Reflcctometry, J.Opt. Soc. Am., 57, 4 (1967) p. 445. Surv Thry
83. Erb, W, Requirements for Reflection Standards and the Measurement of Their Reflection Values, Appl. Opt., 14, 2 (Feb. 1975) p. 493. Aprt Calb Expt Matl Stnd

84. Kepros, J., and Davis, L., Comparison of Two BRDF Measuring Systems, SPIE Proceedings, 675 (1986) p. 34. Aprt

85. Klicker, K. A., Stover, J. C., Cheever, D. R., Cady, F. M., Practical Reduction of Instrument Signature in Near Specular Light, SPIE Proceedings, 749 (1987).

Desn Inst

86. Klicker, K. A., Stover, J. C., and Wilson, D. C., Near Specular Scatter Measurement Techniques for Curved Samples, SPIE Proceedings, 967 (1988) .

Desn Inst

87. Kung, G. C., Scattering of Baffle Vane Edges, SPIE Proceedings, 511 (1984)

Aprt Desn Stra

88. Lange, S. R., and Parks, R. E., Characterization of Scattering from Diamond-Tumed Surfaces, SPIE Procecdings, 257 (1980) .

Expt Prof Topo

89. Lastovka, J. B., An Optical Apparatus for Very-SmallAngle Light Scattering-Design, Analysis and Performance, Bell Syst. Tech. J., 55, 9 (1976) p. 1225.

Aprt Calb Desn Diff Surv

90. Lee, W. W., Scherr, L. M., and Barsh, M. K., Stray Light Analysis and Suppression in Small Angle BRDF/BTDF Measurement, SPIE Proceedings, 675 (1986). Aprt Desn Inst Stra Thry

91. Leonard, T. A., Introduction to the Relationship Between Surface Roughness and BRDF, (April 1989) (Available from author).

Expt Prof Stnd Sury

92. Leonard, T.A., BRDF Round Robin, SPIE Proceedings, 967 (1988) . Expt Matl Stnd Sury

93. Leonard, T., The Art of Optical Scatter Measurement, 20th Symposium on Optical Materials for High Power Lasers, Boulder, CO, (1988) . Aprt Desn

94. Locke, B. R., and Donovan, R. P., Particle Sizing Uncertainties in Laser Scanning of Silicon Wafers, J. Electrochem. Soc., (July 1987) p. 1763.

Aprt Desn Expt Matl Thry

95. Lovik, M., and Scheeline, A., Active Polarization Compensation and Goniometer for Angularly Resolved Light Scattering Measurements, Appl. Opt., 27, 23 (1988) p. 4931. Aprt Desn Pol

96. Mahahan, V. N., Uniform Versus Gaussian Beams: A Comparison of the Effects of Diffraction, Obsuration, and Aberrations, J. Opt. Soc. Am, 3, 4 (1986) p. 470-485. Abs Diff Thry

97. Marchand, E., and Wolf, E., Radiometry with Sources of Any State of Coherence, J. Opt. Soc. Am., 64, 9 (1974) p. 1219. Coh Thry

98. Marron, J., and Schroeder, K., Speckle from Rough Rotating Objects, Appl. Opt., 27, 20 (1988) p. 4279. Coh Thry

99. McGary, D. E., Stover, J. C., Rifkin, J., Cady, F. M., and Cheever, D. R., Separation and Measurement of Surface Scatter and Volume Scatter from Transparant Optics, SPIE Proceedings, 967 (1988).

Expt Matl 
100. McNeil, J. R., and Al-Jumaily, G. A., Optical Scatter Characteristics and Surface Effects in Coated Metal Surfaces, SPIE Proceedings, 675 (1986) . Expt Matl Prof Topo

101. Metwalli, S., Kamel, A., and Saheb, A., Surface Roughness Effect on Laser Speckle Density, SPIE Proceedings, 645 (1986) p. 120. Coh Expt Thry

102. Mielenz, K., Aberrations of Ellipsoidal Reflectors for Unit Magnification, Appl. Opt., 113, 12 (1974) . Abs

103. Munis, R. H., and Finkel, M. W., Goniometric Measurements of Infrared Transmitting Materials, Appl. Opt., 7, 10 (October 1968) p. 2001.

Aprt Expt Thry Tran

104. Nahm, K., and Wolfe, W., Light Scattering by Polystyrene on a Mirror, SPIE Proceedings, 675 (1986) .

Expt Matl

105. Nicodemus, F., Reflectance Nomenclature and Directional Reflectance and Emissivity, Appl. Opt., 9, 6 (1970) p. 1474.

Surv Thry

106. Nicodemus, F., Directional Reflectance and Emissivity of an Opaque Surface, Appl. Opt., 4, 7 (1965) p. 767.

Surv Thry

107. Nicodemus, F., Comment on Current Definitions of Reflectance, J. Opt. Soc. Am., 66, 3 (1976) p. 283.

Surv Thry

108. Nicodemus, F. E., Richmond, J. C., Hsia, J. J., Ginsberg, I. W., and Limperis, T., Geometrical Considerations and Nomenclature for Reflectance, NBS Monograph 160 (October 1977).

Calb Desn Stnd Surv Thry

109. Noll R., and Glenn, P., Mirror Surface Autocovariance Functions and Their Associated Visible Scattering, Appl. Opt., 21, 10 (1982) p. 1824.

Expt Matl Prof Thry Topo

110. Noll, R. J., Effect of Mid- and High-Spatial Frequencies on Optical Performance, Opt. Eng., 18, 2 (1979) p. 137. Expt Matl Thry Topo

111. O'Donnell, K., and Mendez, E., Experimental Study of Scattering from Characterized Random Surfaces, J. Opt. Soc. Am., A., 4, 7 (1987) p. 1194.

Aprt Expt Prof Thry Topo

112. Orazio, F., Jr., Stowell W., and Silva, R., Instrumentation of a Variable Angle Scatterometer (VAS), SPIE Proceedings, 362 (1986) p. 165. Aprt Desn

113. Pompea, S. M., Bergener, D. W., Shepard, D. F., Russak, S., and Wolfe, W. L., Reflectance Measurements on An Improved Optical Black for Stray Light Rejection from 0.3 to $500 \mu \mathrm{m}$, Opt. Eng., 23, 2 (1984) p. 149. Aprt Expt Matl Stra

114. Pompea, S. M., Shepard, D. F., and Anderson, S., BRDF Measurements at 6328 Angstroms and 10.6 Micrometers of Optical Black Surfaces for Space Telescopes, SPIE Proceedings, 967 (1988). Expt MatI

115. Pompea, S. M., Bergener, D. W., Shepard, D. F., and Williams, K., The Effects of Atomic Oxygen on Martin Black and Infrablack, SPIE Proceedings, 511 (1984).

Expt Matl

116. Porteus, J. D., Relation Between the Height Distribution of a Rough Surface and the Reflectance at Normal Incidence, J. Opt. Soc. Am, 53, 12 (1963) p. 1394. Thry Topo
117. Richmond, J., and Hsia, J., Bibliography on Scattering by Reflection from Surfaces, J. Res. Natl. Bur. Stand. (U.S.), 80A, 2 (1976) p. 207.

Surv

118. Rifkin, J., Klicker, K. A., Bjork, D. R., Cheever, D. R., Schiff, T. F., Stover, J. C., Cady, F. M., Wilson, D. J., Chausse, P. D., and Kirchner, K. A., Design Review of a Complete Angle Scatter Instrument, SPIE Proceedings, 967 (1988).

Aprt Desn

119. Rifkin, J., Stover, J. C., McGary, D. E., Kirchner, K. H., and Wilson, D. J., Raster Area Scatter Measurements and Sample Uniformity, SPIE Proceedings, 967 (1988). Desn Expt

120. Roche, P., and Pelletier, E., Charactcrization of Optical Surfaces by Measurement of Scattering Distribution, Appl. Opt., 23, 20 (October 15, 1984) p. 3561.

Aprt Expt Inst Thry Topo

121. Rowe, T. S., Comparison of Scatter from Diamond Turned Optics to Conventionally Formed Optics in the Visible Wavelengths, SPIE Proceedings, 818 (1988). Expt Matl Topo

122. Scheels, S. F., Scattering from Infrared Transparent Materials, SPIE Proceedings, 107 (1977) p. 48.

Aprt Expt Matl Tran

123. Scherr, L. M., Schmidt, J. H., and Sorensen, K., BRDF of Silicon Carbide and Aluminum Foam Compared to Black Paint at 3.39 Microns, SPIE Proceedings, 1165 (1989). Expt Matl Stra

124. Schiff, T. F., Stover, J. C., Cheever, D. R., and Bjork, D. R., Maximum and Minimum Limitations Imposed on BSDF Measurements, SPIE Proceedings, 967 (1988). Desn Inst Thry

125. Shirley, L., and George, N., Diffuser Radiation Pattcrns Over a Large Dynamic Range. 1. Strong Diffusers, Appl. Opt., 27, 9 (1988) p. 1850.

Coh Thry Topo

126. Shirley, L., and George, N., Wide-Angle Diffuser Transmission Functions and Far-Zone Speckle, J. Opt. Soc. Am., A, 4, 4 (1987) p. 734.

Coh Thry Tran

127. Silva, R., Orazio, F., Jr., and Stowell, W., Scatter Evaluation of Supersmooth Surfaces, SPIE Proceedings, 362 (1986) p. 71. Expt Topo

128. Silva, R., Orazio, F., and Sledge, R., A New Instrument for Constant $\left(\beta-\beta_{0}\right)$ Scatter Mapping of Continuous Optical Surfaces of up to 25 Square Inches, SPIE Proceedings, 511 (1984).

Aprt Desn Expt

129. Smith, S., Far-Infrared (FIR) Optical Black Bidirectional Reflectance Distribution Function (BRDF), SPIE Proceedings, 257 (1980).

Aprt Expt Matl Thry

130. Smith, S., and Wolfe, W., Comparison of Measurements by Different Instruments of the Far-Infrared Reflectance of Rough, Optically Black Coatings, SPIE Proceedings, 362 (1986) p. 46.

Desn Expt Inst Matl Stnd Surv

131. Smith, S. M., Far-Infrared Reflectance Spectra of Optical Black Coatings, SPIE Proceedings, 362 (1986) p. 57. Expt Matl Thry

132. Spyak, P., and Wolfe, W., Cryogenic Scattering Measurements, SPIE Proceedings, 967 (1988).

Aprt Desn Expt 
133. Stierwalt, D. L., Infrared Absorption of Optical Blacks, Opt. Eng., 18, 2 (1979) p. 147.

Expt Mat

134. Stover, J. C., Roughness Characterization of Smooth Machined Surfaces by Light Scattering, Appl. Opt., 14, 8 (1975) p. 1796. Expt Prof Thry Topo

135. Stover, J. C., Bernt, M. L., McGary, D. E., and Rifkin, J., An Investigation of Anomalous Scatter From Beryllium Mirrors, Report prepared for Manufacturing Operation Development and Integration Laboratory (MODIL) Engineering Technology Division, Oak Ridge National Laboratory (February 1990).

Expt Matl Topo

136. Stover, J. C., Cady, F. M., and Sklar, E., Measurement of Low Angle Scatter, Opt. Eng., 24, 3 (May/June 1985) p. 404.

Aprt Desn Inst

137. Stover, J., and Gillespic, C., Design Review of Three Reflectance Scatterometers, SPIE Proceedings, 362 (1983). Aprt Inst Prof

138. Stover, J., Gillespie, C., Cady, F., Cheever, D., and Klicker, K., Comparison of BRDF Data From Two Scattcrometers, SPIE Proceedings, 818 (1987). Aprt Expt Matl

139. Stover, J. C., and Hourmand, B., Some Deviations Associated with Vector Perturbation Diffraction Theory, SPIE Proceedings, 511 (1984).

Diff Expt Inst Thry Topo

140. Stover, J. C., Hourmand, B., Kahler, J., and Gillespie, C., Comparison of Roughness Measurements by Differential Scatter and TIS, SPIE Proceedings, 362 (1983). Aprt Expt Prof Surv

141. Stover, J. C., Klicker, K. A., Cheever, D. R. and Cady, F. M., Reduction of Instrument Signature in Near Angle Scatter Measurements, SPIE Proceedings, 749 (1987) p. 46.

Desn Inst

142. Stover, J. C., McGary D. E, and Rifkin, F., Inspection of Large Area and Large Volume Optics by Raster Scanning, SPIE Proceedings, 967 (1988).

Desn Expt Topo

143. Stover, J., Rifkin, J., Cheever, D., Kirchner, K, and Schiff, T., Comparison of Wavelength Scaling Data to Experiment, SPIE Proceedings, 967 (1988).

Expt

144. Stover, J, C, Serati, S. A., and Gillespie, C. H., Calculation of Surface Statistics From Light Scatter, Opt. Eng., 23, 4 (July/Aug 1984) p. 406.

Pol Topo Thry

145. Stuhlinger, T., Dereniak, E., and Bartell, F., Bidirectional Reflectance Distribution Function of Gold-Plated Sandpaper, Appl. Opt., 20, 15 (1981) p. 2648. Aprt Calb Expt Matl Stnd

146. Thompson, C., and Wolfe, W., An Interfcrometric Approach to Suppression of Scattered Radiant Energy, SPIE Proceedings, 511 (1984).

Aprt Stra Thry

147. Torrance, K., Sparrow, E., and Birkebak, R., Polarization, Directional Distribution, and Off-Specular Peak Phenomena in Light Reflectcd from Roughencd Surfaces, J. Opt. Soc. Am., 56, 7 (1966) p. 916.

Expt Pol Thry Topo
148. Venable, W., Jr., and Johnson, N., Unified Coordinate System for Retroreflectance Measurements, Appl. Opt., 19, 8 (1980) p. 1236.

Surv Thry

149. Viehman, W., and Predmore, R. E., Ultraviolet and Visible BRDF Data on Spacecraft Thermal Control and Optical Baffle Materials, SPIE Proceedings, 675 (1986). Expt Matl Stra

150. Vorburger, T., and Teague, E., Optical Techniques for On-Line Measurement of Surface Topography, Prec. Eng, (1981) p. 61. Prof Thry Topo

151. Vorburger, T., Teague, E., Scire, F., McLay, M., and Gilsinn, D., Surface Roughness Studies with DALLASDetector Array for Laser Light Angular Scattcring, J. Res. Natl. Bur. Stand. (U.S.), 89, 1 (1984) p. 3. Aprt Expt Inst Prof

152. Wang, H., and Mi, H., Light Scattering Method, Inspection of Diamond Turning Process, Proceedings from In Process Optical Measurements and Industrial Methods at the International Congress on Optical Science and Engineering in the Ncthcrlands (March 1990).

Expt Thry Topo

153. Wang, Y., Scattering From Mirrors Contaminated By Particulates-II: An Extended Model, NASA Tech Brief, 13, 11 (Novembcr 1989).

Thry Topo

154. Wang, Y., and Wolfe, W., Scattering from Microrough Surfaces: Comparison of Theory and Experiment, J. Opt. Soc. Am., 73 (1983) p. 1596.

Expt Thry Topo

155. Wang, Y., Scattering from Mirrors Contaminated by Particulates: A Model, Appl. Opt., 25, 23 (1986) p. 4222. Thry Topo

156. Warren, A., Simplified Techniques for Estimating Outof-Field Radiation, SPIE Proceedings, 257 (1980). Desn Thry Stra

157. Warren, A. D., Analysis of Out-of-Field Radiation in Reimaging Optical Systems, SPIE Proceedings, 107 (1977) p. 111.

Desn Thry Stra

158. Weidner, V., Hsia, J., and Adams, B., Laboratory Intercomparison Study of Pressed Polytetrafluoroethylene Powder Reflectance Standards, Appl. Opt., 24, 14 (1985) p. 2225.

Calb Expt Matl Stnd

159. Wein, S., and Wolfe, W., Small-Angle Scatteromctcr, SPIE Proceedings, 967 (1988).

Abs Aprt Desn Diff Inst

160. Wein, S. J., and Wolfe, W., Gaussian-Apodized Aperatures and Small-Angle Scatter Measurement, Opt. Eng., 28, 3 (1989) p. 273. Abs Aprt Desn Diff Inst

161. Williams V., and Lockie, R., Optical Contamination Assessment by Bidirectional Reflectance-Distribution Function (BRDF) Measurement, Opt. Eng., 18, 2 (1979) p. 152. Aprt Expt Thry Topo

162. Wojcik, G. L., Vaughan, D. K., and Galbraith, L. E., Calculation of Light Scatter from Structures on Silicon Surfaces, SPIE Proceedings, 774 (March 1987). Desn Inst Matl Thry Topo

163. Wolfe, W. L., Scattered Thoughts on Baffling Problems, SPIE Proceedings, 256 (1980).

Desn Stra 
164. Wolfe, W., Bartell, R. O., and Brooks, L. D., Description and Limitations of an Automated Scatterometer, SPIE Proceedings, 362 (1986).

Inst Stnd

165. Wolfe, W., Hubbs, J., and Bartell, F., Scatter Measurements on LAK9 and SF1 Glasses at 0.915 Micrometers, SPIE Proceedings, 429 (1983).

Expt Matl

166. Wolfe, W., Magee, K., and Wolfe, D., A Portable Scatterometer for Optical Shop Use, SPIE Proceedings, 525 (1985) p. 160.

Aprt Desn Inst

167. Wolfe, W., and Wang, Y., Comparison of Theory and Experiments for Bidirectional Reflectance Distribution Function (BRDF) of Microrough Surfaces, SPIE Proceedings, 362 (1986) p. 40.

Expt Pol Thry Topo

168. Wong, W., Small Angle Bidirectional Reflectance Distrjbution Function (BRDF) at $10 \mu \mathrm{m}$, SPIE Proceedings, 430 (1983).

Aprt Desn Expt Inst

169. Young, R. P., Degradation of Low Scatter Mirrors By Particle Contamination, AIAA Paper No.A75-32905 (1975). Aprt Expt Thry Topo

170. Young, P. J., Noll, R., Andreozzi, L., and Hope, J., Particle Contamination from Martin Optical Black, SPIE Proceedings, 257 (1980).

Desn Expt Matl Stra Thry

171. Young, R. P., Mirror Scatter Measurements Facility Comparison, report no. AEDC-TR-75-68 (1975).

Inst Surv

About the Author: Clara Asmail is a physicist in the Radiometric Physics Division, National Institute of Standards and Technology. 